\title{
Wolfgang Groepler \\ Ovulation in Diplosoma (Tunicata, Ascidiacea, Didemnidae): a light microscopical study
}

Received: 13 August 2001 / Revised: 2 April 2002 / Accepted: 3 April 2002 / Published online: 23 May 2002

C) Springer-Verlag and AWI 2002

\begin{abstract}
Serial sections of non-ovulated and ovulated eggs of Diplosoma migrans (Tunicata, Ascidiacea, Didemnidae) were compared in order to study the process of ovulation on the level of light microscopy. Fully grown eggs are surrounded by an outer follicular epithelium consisting of cubic cells, and an inner follicular epithelium consisting of flat cells. Egg release is initiated by a fusion of the epidermis with the outer follicular epithelium at the distal pole of the egg. A contraction of the outer follicular epithelium leads to an opening of both epidermis and outer follicular epithelium, and their removal from the egg. The envelope of ovulated eggs corresponds to the former inner follicular epithelium. Mainly due to a contraction of the epidermis, the outer follicular epithelium is shifted into the abdomen and separates from the epidermis. It transforms into a vestigial body (corpus luteum) and finally atrophies. The epidermis flattens and resumes its typical appearance. On the basis of these observations, the results of studies on the closely related Diplosoma listerianum are discussed and questioned.
\end{abstract}

Keywords Ascidians · Egg envelopes - Ovulation

\section{Introduction}

Mature eggs of the Didemnidae (Tunicata, Ascideacea) are very large in relation to zooid body size, and thus cannot be released via the oviduct. Nevertheless, in contrast to some reports (Salensky 1894; Fechter 1971), the oviduct persists as an inconspicuous structure (Groepler 1997). It allows sperm to reach the eggs inside the ovary, where fertilization takes place (Burighel and Martinucci

Communicated by H.-D. Franke

W. Groepler (

Pädagogische Hochschule Karlsruhe, Fakultät III, PO Box 4960,

76032 Karlsruhe, Germany

e-mail: groepler@ph-karlsruhe.de

Tel.: +49-721-9254254, Fax: +49-721-9254249
1994). Didemnids have evolved a special mechanism of direct release of eggs from the body. Eggs reach the common tunic of the colony where they develop into larvae. These ultimately leave the colony via the cloacal aperture.

There are two different views of how ovulation occurs in didemnids: (1) eggs leave the zooids through a rupture in the ectoderm (Milne Edwards 1842; Gegenbaur 1862; Lahille 1890; Lafargue 1968); (2) eggs detach from the abdomen by some kind of budding, with the epidermis transforming into the outer envelope containing the eggs (Ganin 1870; Salensky 1894). It was only recently that, in Diplosoma listerianum, ovulation has been studied in more detail (Burighel et al. 1987; Martinucci et al. 1988). As to the origin of the envelope of deposited eggs, the authors basically took the view of Ganin and Salensky. Furthermore, attention was focused on the fate of the follicle cells. Ascidian eggs are typically wrapped by both an inner and an outer follicular epithelium. Briefly, ovulation is said to occur as follows: eggs first lose their two follicular envelopes, the inner envelope decays, and the outer one retracts from the egg and transforms into a vestigial body inside the abdomen. After this process, the egg is surrounded only by the epidermis. The egg and the surrounding epidermis form a protruding "bud" on the surface of the abdomen. A circular rupture of the epidermis at the basis of this "bud" ultimately leads to the egg's segregation from the abdomen. The abdominal wound is then closed rapidly.

This view of the ovulation process in Diplosoma listerianum is in contrast to what is hitherto known from other ascidians: In these, the envelope of ovulated eggs is considered to represent the inner folicular epithelium (see Berrill 1950; Mukai 1977; Satoh 1994). The light microscopical investigations reported in this paper were performed to clarify the ovulation process in didemnids. The results clearly suggest that the origin of the envelope of ovulated eggs corresponds to what appears to be typical of ascidians, and that ovulation occurs in an essentially different way from that was reported by Burighel et al. (1987) and Martinucci et al. (1988). 
Fig. 1 Zooid of Diplosoma migrans with egg before (a) and after (b) ovulation. $A$ abdomen, $E$ egg before ovulation, $E p$ epidermis, $H$ hindgut, $O E$ ovulated egg, $T$ thorax, $V$ vestigial body. Bar represents $100 \mu \mathrm{m}$

Fig. 2 Fully grown primary oocyte, with central nucleus. $E p$ epidermis, $G$ granulocytes between epidermis and OFE, $O F E$ outer follicular epithelium (consisting of cubic cells), Tu tunic. Bar represents $100 \mu \mathrm{m}$
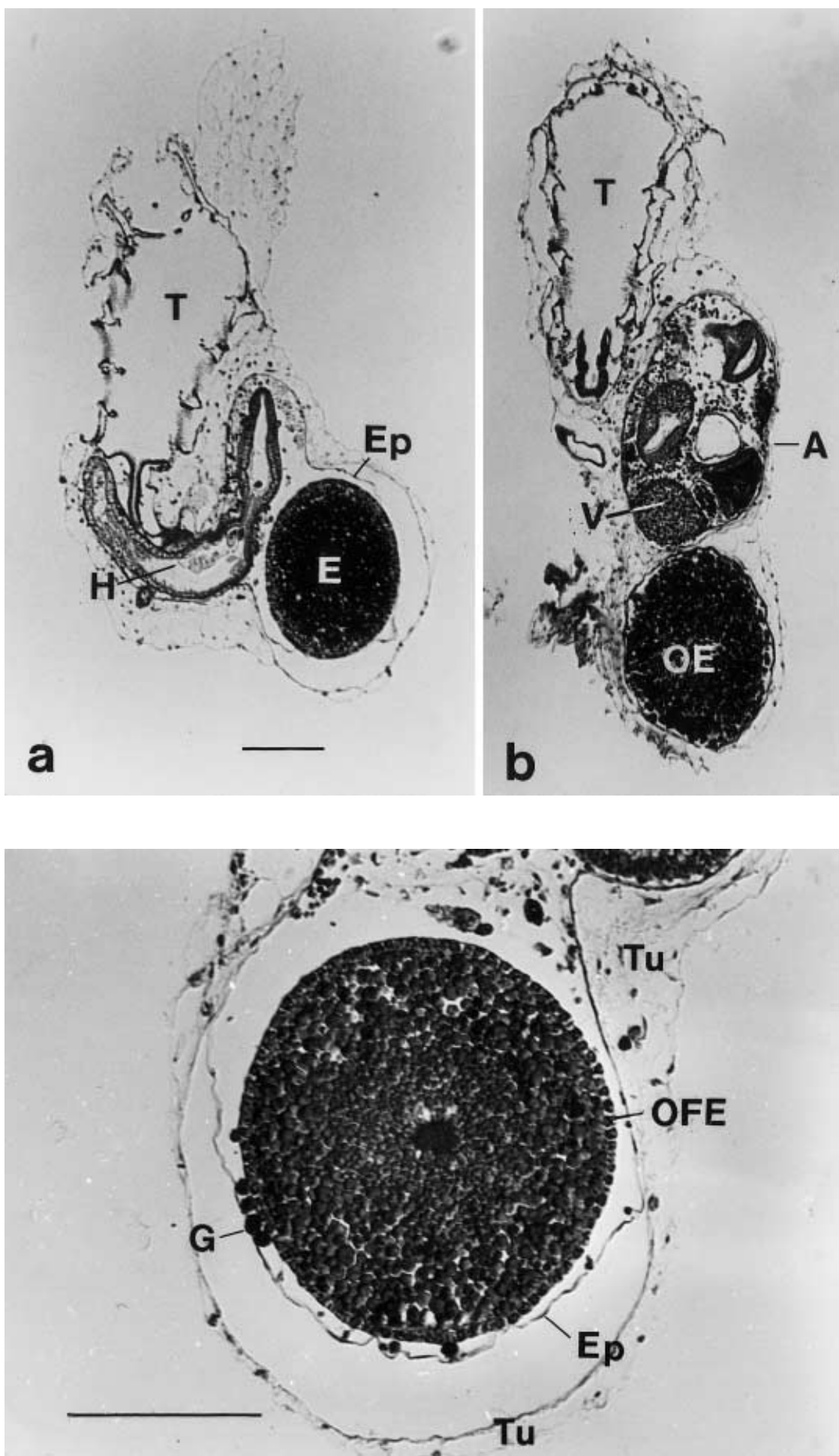

\section{Material and methods}

The investigations were mainly carried out on Diplosoma migrans; a small number of Diplosoma listerianum served for comparison. Colonies of both species were collected at Helgoland (German Bight, North Sea). The animals were mostly anaesthetized with cocaine and then fixed in Bouin's solution. A small number of specimens were fixed directly in buffered glutaraldehyde. The material was embedded into paraffin or, in a few cases, into the synthetic technovit. For histological examination the eggs were cut in serial sections of $5 \mu \mathrm{m}$ (paraffin) and $3 \mu \mathrm{m}$ (technovit) thickness, respectively. The sections were stained with azan according to Heidenhain or haematoxylin/eosin (technovit), which both furnished good results. The examination of several hundred zooids revealed both non-ovulated and ovulated eggs, but not a single egg that had been fixed at the very moment of ovulation. To obtain eggs fixed in the moment of ovulation, it appears necessary to identify this particular stage under the microscope before fixation. 
Fig. 3a, b Mature egg, ready for ovulation. a General view; epidermis and OFE largely lifted from the egg (artifact); IFE tightly surrounding the oocyte; polar body (with small yolk granulum) and several isolated test cells at the distal pole of the egg between IFE and chorion. b Detail, corresponding to box in a; test cells between chorion and IFE; OFE and epidermis tightly connected to each other. $C$ chorion, $E p$ epidermis, IFE inner follicular epithelium, $O F E$ outer follicular epithelium, $P$ polar body, Te test cells. Bars represent $50 \mu \mathrm{m}$ (a), $25 \mu \mathrm{m}$ (b)

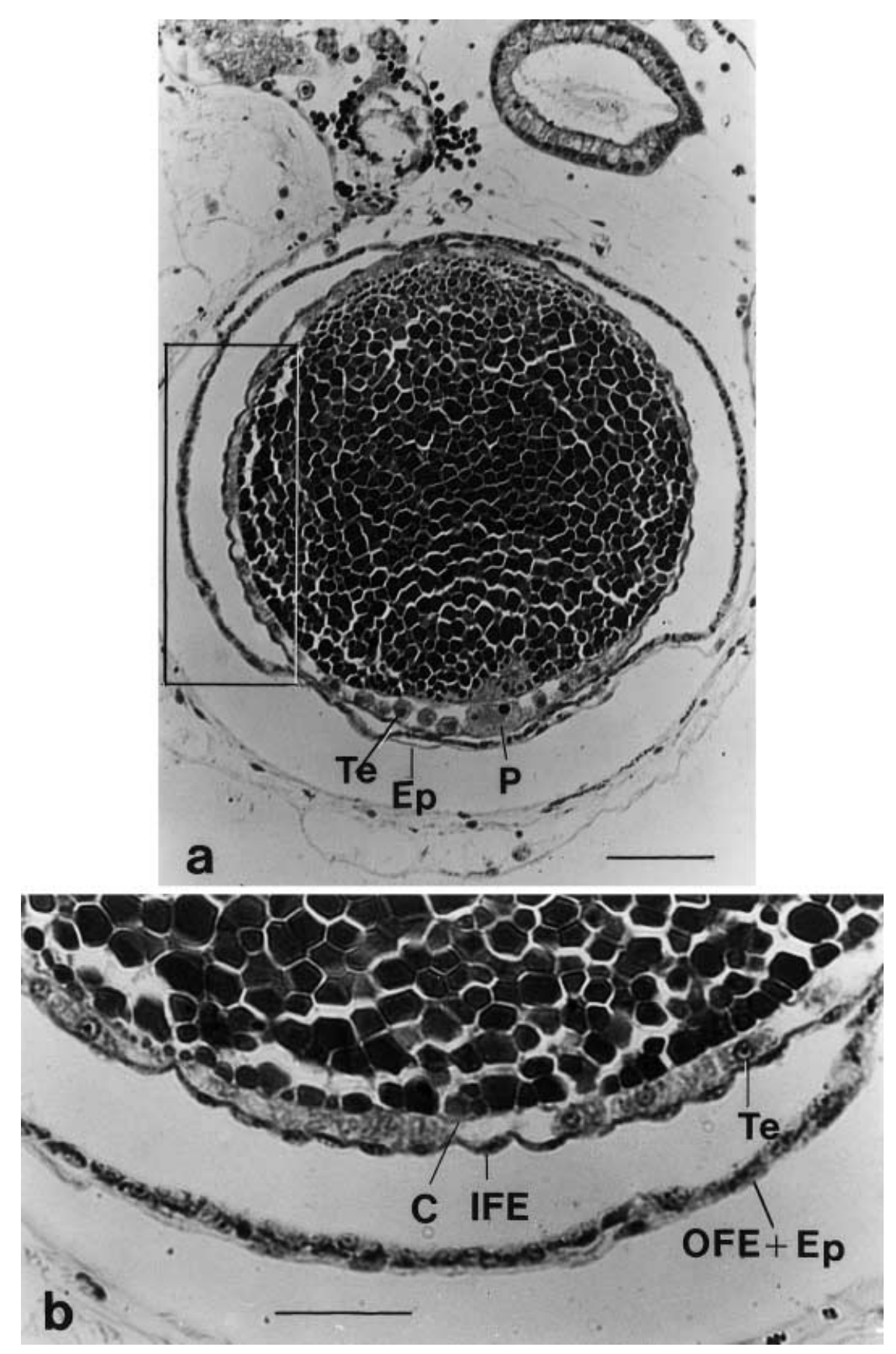

\section{Results}

Unless otherwise stated the results refer to D. migrans.

The egg before ovulation

Figure 1a shows a zooid with an egg inside an abdominal bulge. The surrounding epidermis is a thin squamous epithelium with occasional pigment granules. The nuclei of these epithelial cells are usually elongated, while they are rather round or oval in the rest of the abdomen. A fixed fully grown egg is round and about $200 \mu \mathrm{m}$ in diameter (Fig. 2). The oval shape of eggs shown in Fig. 1 is an artifact resulting from the cutting procedure. The egg plasma is completely filled with yolk particles. The nucleus is central and irregular in shape; it contains a round nucleolus and is surrounded by a narrow plasmatic zone. The egg envelope (Figs. 3, 4) consists of a chorion followed outwards by two cellular layers, the inner and the outer follicular epithelium (IFE and OFE).

Associated with fully grown primary oocytes there are more or less abundant granulocytes scattered between epidermis and OFE (Figs. 2, 4a). Eggs of a more advanced stage, which are characterized by a flat OFE, show only a small number of granulocytes in this area, while granulocytes can then be found between OFE and 
Fig. 4a-c Cortex and envelopes. a Primary oocyte; OFE consisting of cubic cells; IFE cells with conspicuous nuclei; test cells in the cortex of the oocyte; granulocytes between epidermis and basement membrane of OFE. b Egg ready for ovulation; OFE consisting of flattened cells; epidermis, OFE and IFE tightly connected to each other, with granulocytes underneath. c Same stage as in b, but with epidermis, OFE (with fattened cells) and IFE clearly separated from each other. $B$ basement membrane, $E p$ epidermis, $G$ granulocytes, IFE inner follicular epithelium, $O F E$ outer follicular epithelium, $T e$ test cells, Tu tunic. Bars represent $25 \mu \mathrm{m}$

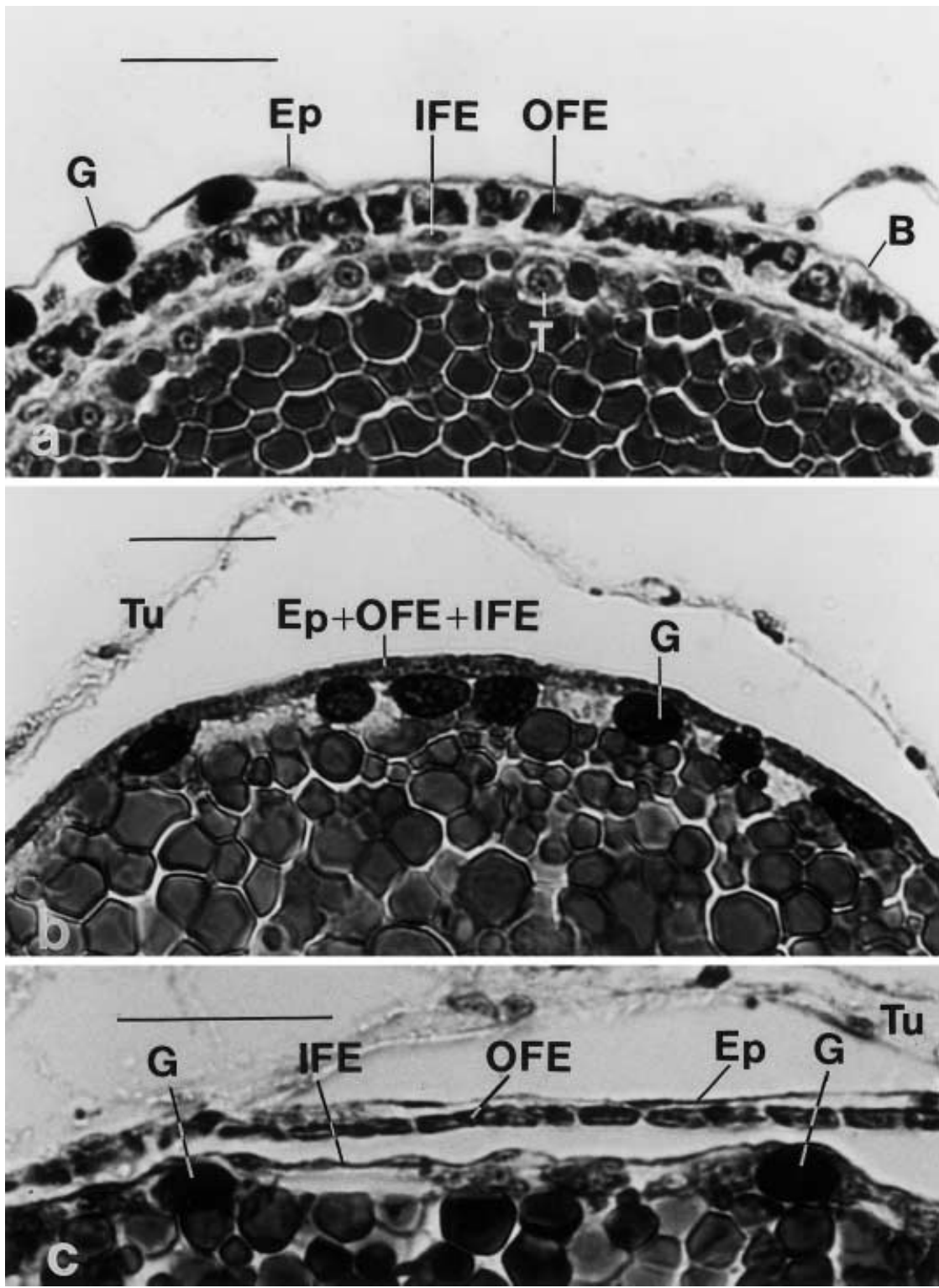

IFE, and particularly in the perivitelline space between IFE and the chorion (Fig. 4b, c).

The OFE consists of cubic cells (height/width up to about $7 \mu \mathrm{m}$ ) which rest on a basement membrane facing the abdominal cavity (Fig. 4a). In eggs approaching the stage of ovulation, these cells flatten more and more. Figure $4 \mathrm{c}$ shows a thin squamous OFE with cells flattened to about $2 \mu \mathrm{m}$ in height.

The IFE consists of flat cells. In primary oocytes, it can hardly be decided whether these cells are actually connected to each other forming a true epithelium (Fig. 4a). In older (secondary) oocytes, however, the IFE undoubtedly consists of a compact cell layer (Figs. 3, 4c).

In young eggs, large numbers of test cells occur in the cortex area, scattered among yolk particles. In the stage of a flat OFE (which presumably corresponds to the secondary oocyte stage), these cells have left the cortex and can be found between chorion and IFE, either iso- lated from each other or forming a compact layer here and there (Fig. 3).

\section{Ovulation}

As already mentioned, not a single zooid in the very phase of ovulation could be found among the fixed Diplosoma colonies. Apparently, ovulation is completed within a very short period of time. This assumption could be confirmed by directly observing ovulation under a stereomicroscope. Ovulation started with a fine circular constriction at the egg's distal pole. This constriction then advanced rapidly towards the egg's equator. It took less than half a minute for ovulation to complete.

Figure 5 shows a section through a just-ovulated egg. It is completely (i.e. including the proximal pole) surrounded by a thin epithelium (Fig. 5b, c). A compar- 


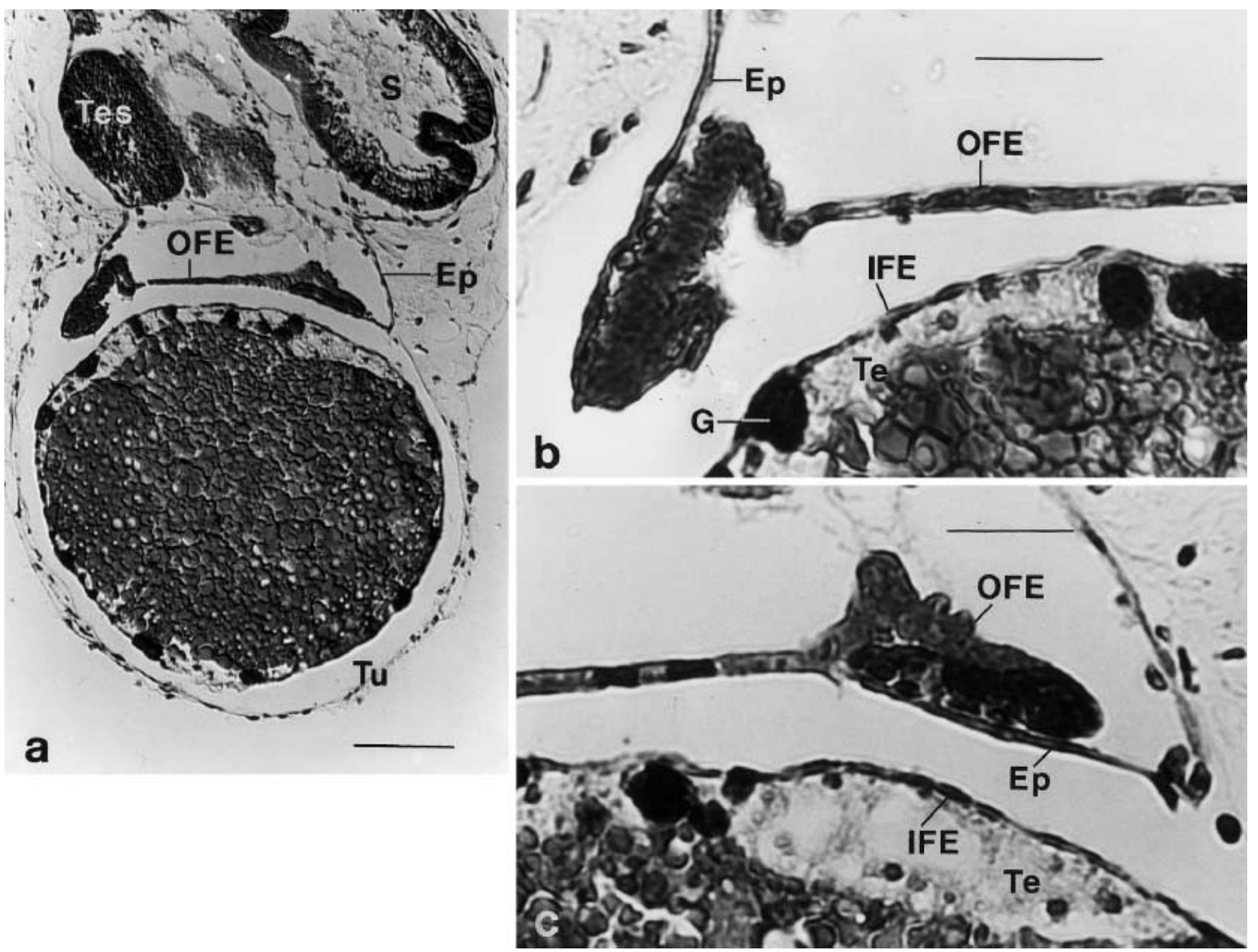

Fig. 5a-c Egg immediately after ovulation. a General view; egg completely surrounded by an envelope which corresponds to the IFE; broad proximal part of the envelope containing test cells and granulocytes; OFE retracted from the egg, its strongly contracted lateral parts passing into the epidermis. b, c Details from a section next to a; contracted OFE, fused with epidermis; opposite egg surface covered by complete layer of IFE cells. Ep epidermis, $G$ granulocytes, IFE inner follicular epithelium, $O F E$ outer follicular epithelium, $S$ stomach, Te test cells, Tes testis. Bars represent $50 \mu \mathrm{m}(\mathbf{a}), 20 \mu \mathrm{m}(\mathbf{b}, \mathbf{c})$

ison clearly shows that the envelope of just-ovulated eggs originates from the IFE of pre-ovulation eggs. Furthermore, Fig. 5 shows that the OFE has withdrawn from the egg by means of contraction: the different thickness of the OFE indicates that, at the moment of fixation, the OFE at the proximal pole had not yet been much affected by this process, compared with other parts of the OFE. Finally, Fig. 5b, c shows that the epidermis is closely connected with the retracting OFE and takes part in the process of retraction from the very beginning. The epidermis apparently retracts under slight thickening.

Considering that the epidermis and the OFE are closely connected to each other when retracting from the egg, it may be assumed that some kind of tissue fusion is involved in the opening mechanism. After ovulation the OFE blocks the abdomen for a while. The edges of the OFE, which at first diverge considerably (Fig. 5b), gradually approach each other giving rise to an open blister. Its thick inner wall is formed by the OFE, which at the opening passes into the epidermis (Fig. 6a). This process is probably driven by a continuing contraction of the OFE and/or the connected epidermis. Participation of the latter is suggested by the observation that the epidermal cells take a columnar shape. The height of the epidermal cells decreases from the opening of the blister towards the periphery (Fig. 6a), suggesting that the intensity of contraction decreases in the same direction. Even after the opening has closed, the process of contraction seems to continue for a while. The cells in the centre of contraction, are pressed out into the space between abdomen and ovulated egg (Fig. 6b) and are partly rejected by the epithelium (Fig. 7). Later on one can find them scattered in the tunic, undergoing degeneration. The epidermal cells flatten more and more (Fig. 6c) and finally do not differ from those of other areas.

As a result of contraction, the OFE becomes an isolated structure underneath the epidermis. From this stage 
Fig. 6a-c Transformation of contracted OFE into vestigial body. a Retracted OFE opposite the proximal pole of the ovulated egg, forming the wall of a blister which opens to the outside. An asterisk marks the area where epidermis and former OFE are fused; epidermis thickened by contraction. b Blister closed, transforming into vestigial body, which is still connected to the epidermis; epidermis cells around the former opening area emerge from the epithelium. c Vestigial body separated from the epidermis, atrophying and without lumen; epidermis flattened; accumulations of granulocytes both beneath epidermis and within atrophying vestigial body. $E$ egg cell, $E p$ epidermis, $G$ granulocytes, $C$ coat of the egg (= inner follicular epithelium), $O F E$ outer follicular epithelium, $P$ protuberance of epidermal cells, $V$ vestigial body. Bars represent $50 \mu \mathrm{m}$ (a), $25 \mu \mathrm{m}(\mathbf{b})$ and $30 \mu \mathrm{m}(\mathbf{c})$
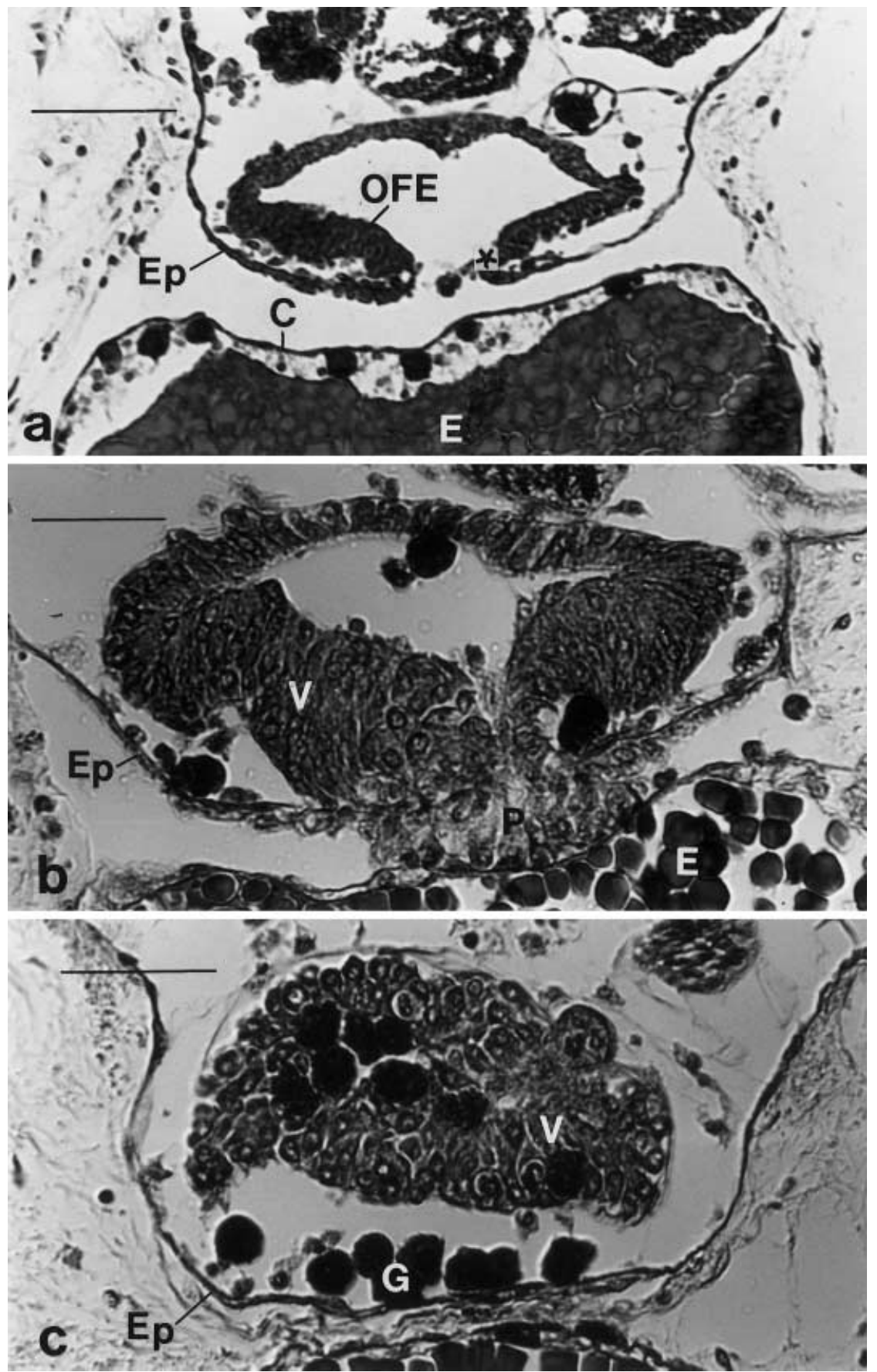

on the OFE is referred to as vestigial body (corpus luteum by other authors). For some time it exhibits a large lumen, which disappears when the vestigial body atrophies (Figs. 6c, 7). This atrophy may be caused by granulocytes, which can be found in both the lumen and the tissue of the vestigial body until its very end (Fig. 6c). In its final stage the vestigial body is a narrow cord, surrounded by a thick basal membrane and containing degenerating cells. Its connection to the ovary persists until its very end (Fig. 8). The oval shape of eggs shown in Fig. 8 is an artifact resulting from the cutting procedure.
Primary oocytes of $D$. listerianum exhibit significantly more granulocytes between epidermis and OFE than those of D. migrans. They are chiefly found at the distal egg pole where they can form a solid cap consisting of two or three cell layers (Fig. 9a). As in D. migrans, older eggs of $D$. listerianum (with flattened OFE) exhibit granulocytes in the perivitelline space (Fig. 9b).

Figure 10 shows a diagrammatic representation of the ovulation process in Diplosoma, summarizing the above findings. 
Fig. 7 Rejection of (supernumerary) epidermal cells when these flatten above the vestigial body, resuming their typical appearance. Ep epidermis, $P$ protuberance of epidermal cells, $V$ vestigial body. Bar represents $50 \mu \mathrm{m}$

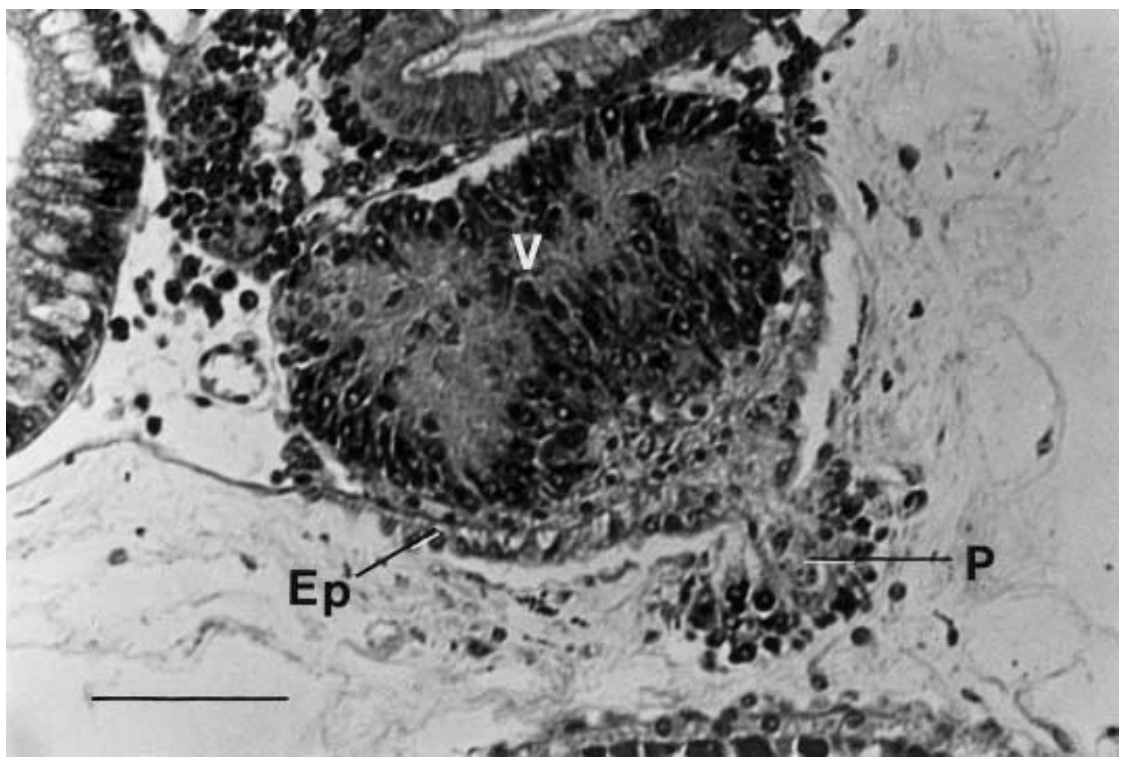

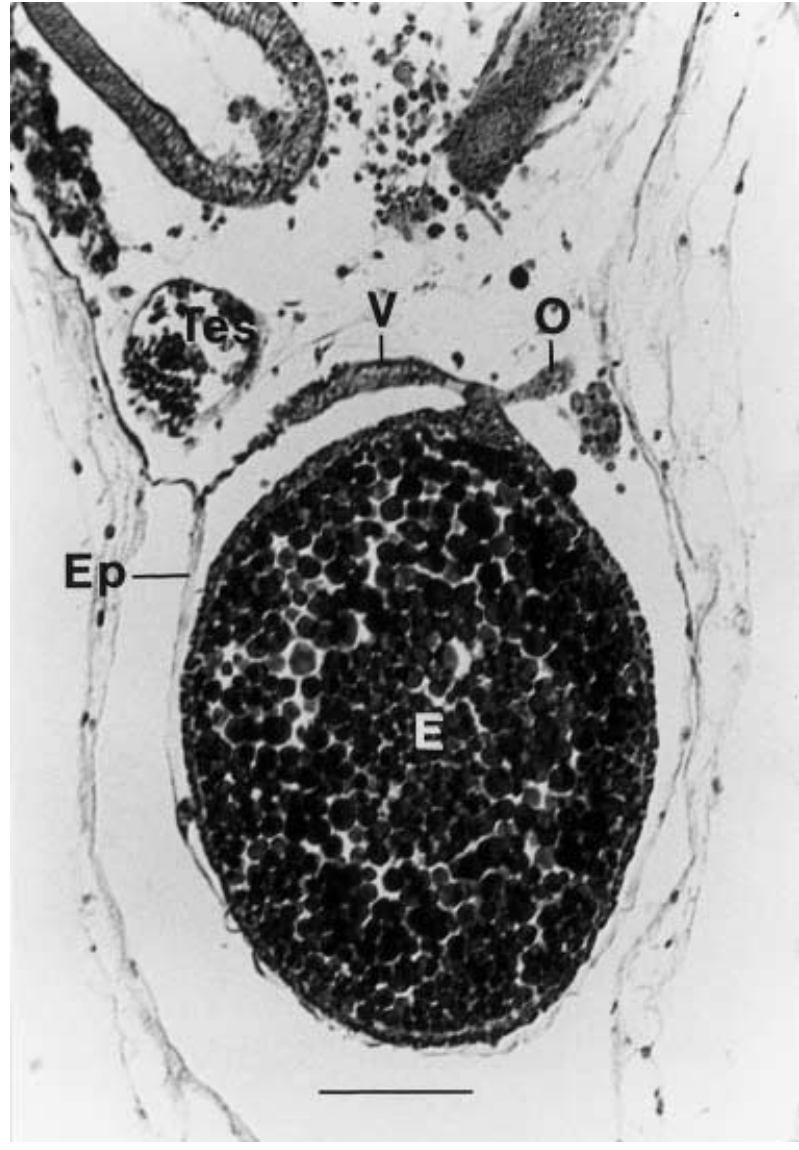

Fig. 8 Final stage of the vestigial body. Vestigial body reduced to a cordlike structure still connected to the ovary (and, in this special case, to the epidermis). $E$ egg (before ovulation), $E p$ epidermis, $O$ ovary, Tes testis, $V$ vestigial body. Bar represents $50 \mu \mathrm{m}$.

\section{Discussion}

Outer follicular epithelium (OFE) and granulocyctes

When eggs approach ovulation, granulocyctes accumulate between epidermis and OFE. In D. migrans they appear only in small numbers and are mainly scattered; in D. listerianum, however, granulocytes form multicellular cap-like structures. Presumably based on this observation, Martinucci et al. (1988) claimed a decisive role of granulocytes in the ovulation process in D. listerianum: When passing through the OFE, granulocytes were said to separate the cells of this epithelium, thus initiating the retraction of the OFE from the egg. As shown in this paper, however, granulocytes in both $D$. migrans and D. listerianum accumulate in the perivitelline space while the cells of the OFE still form a continuous and compact epithelium. This clearly indicates that the passage of granulocytes does not result in loosening and disintegration of the OFE and thus cannot be involved in the removal of the OFE from the egg.

Inner follicular epithelium (IFE)

Martinucci et al. (1988) did not give a consistent description of the structure of the IFE in D. listerianum. While these authors described the IFE as a layer of loosely arranged cells which are connected sporadically to one another, their diagram shows a IFE consisting of completely separated cells. In the present investigation on D. migrans, the IFE proved to be a continuous layer, and this might apply to the closely related $D$. listerianum as well.

According to Martinucci et al. (1988), the IFE is retracted from the egg together with the OFE at the start of ovulation. If this was right, we would expect to find remains of the IFE (a retracted epithelium or cell accumu- 
Fig. 9a, b Egg cells of Diplosoma listerianum. a Fully grown primary oocyte (general view); tightly packed granulocytes forming two (typically only one) caplike structures between epidermis and OFE at the distal pole of the egg. b Secondary oocyte (distal surface); cap disintegrated; a small number of granulocytes still outside the OFE, but most inside; some granulocytes within the OFE, probably fixed at the moment of passage. In a more advanced stage, all granulocytes occur within the OFE. $E p$ epidermis, $G$ granulocytes, $K$ cap formed by granulocytes $O F E$ outer follicular epithelium, $T u$ tunic. Bars represent $100 \mu \mathrm{m}(\mathbf{a}), 25 \mu \mathrm{m}$ (b)

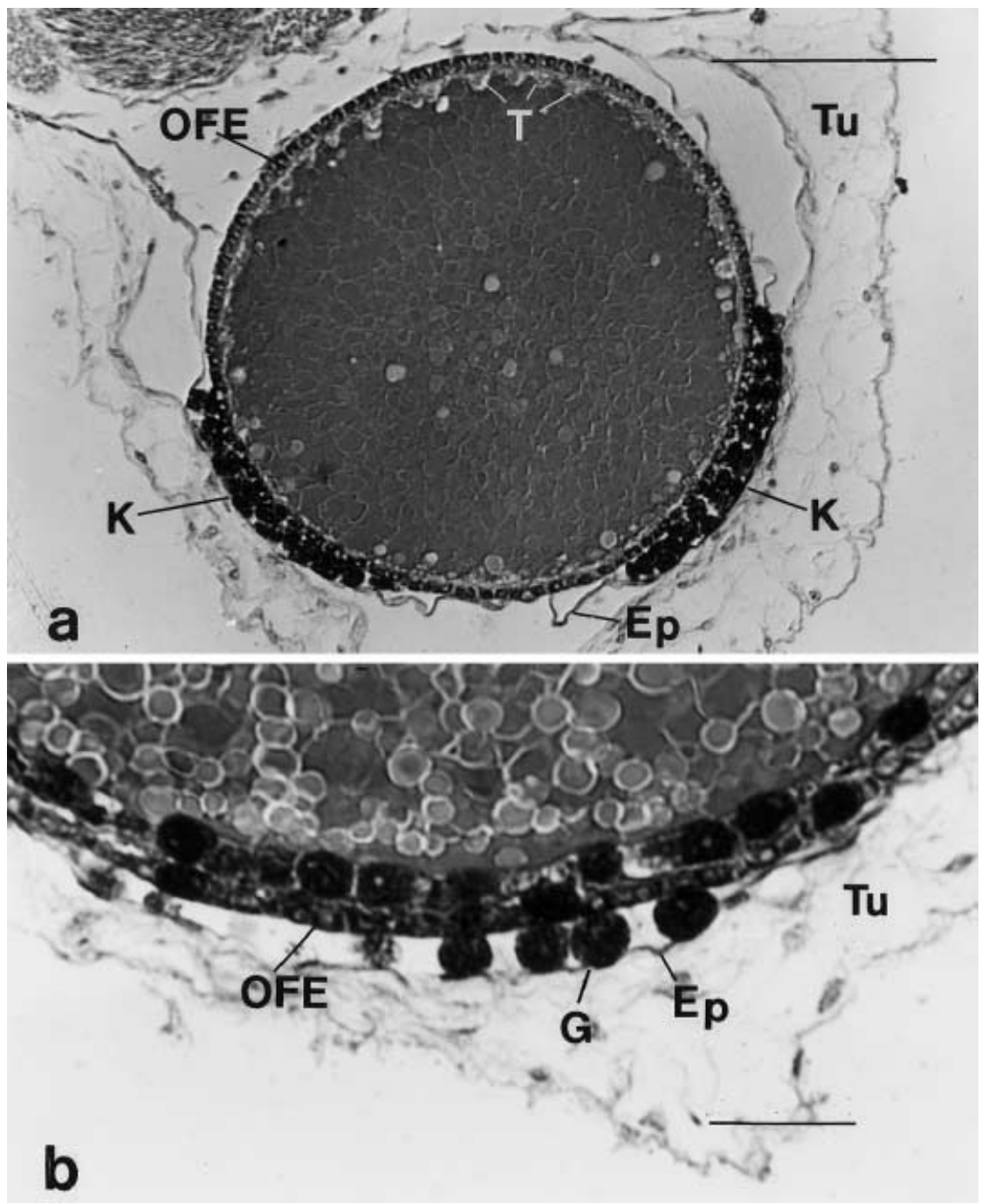

lations) after ovulation in some place or another (e.g. in the vestigial body). Such remains, however, have never been found, indicating that the fate of the IFE in D. listerianum does not differ from that in D. migrans where the IFE is clearly preserved during ovulation.

Test cells

This assumption is also supported by the fate of the test cells. Test cells in D. migrans get out of the cortex area of the egg and accumulate in the perivitelline space some time before ovulation starts. This has also been reported for D. listerianum (Burighel and Martinucci 1994). If Martinucci et al. (1988) were right with respect to the IFE, at least some test cells should be transported along with the retracting OFE and IFE into the lumen of the vestigial body. This, however, is not the case. Test cells are apparently protected by and hidden under a persisting continuous layer of the IFE.

\section{Course of ovulation}

At the start of ovulation, the egg (i.e. the egg cell surrounded by its diverse envelopes) is located within a bud-like epidermal protrusion of the abdomen. Ovulation in D. listerianum is said to occur as described in the following paragraph (Martinucci at al. 1988).

Granulocytes cause an opening of the OFE at the distal pole of the egg. OFE and IFE retract from the egg cell. The remains of the OFE form a plug within the basis of the epidermal bud, i.e. between the proximal pole of the egg and the abdomen. The epidermal bud with the egg cell inside is separated from the abdomen by means of a circular fissure at the base of the bud. This results in a wound both on the proximal egg surface and on the opposite surface of the abdomen. The former is closed rapidly: the epidermis spreads until the edges of the wound touch and fuse. In this way the ovulated egg within the common tunic of the colony becomes completely surrounded by the epidermis. The abdominal wound is provisionally sealed by the plug (former outer follicle cells); by means of strong cellular contractions, 
Fig. 10a-f Diagrammatic representation of the ovulation process in Diplosoma migrans. a Mature egg inside an abdominal bulge; egg cell surrounded by flattened IFE and cubic OFE; cell cortex interspersed with test cells; granulocytes between OFE and epidermis. b Egg at the beginning of ovulation; OFE flattened; at the distal pole (arrow) fusion of epidermis and OFE (followed by an opening of both epithelia); perivitelline space (between IFE and chorion) filled with test cells and granulocytes. c OFE and fused epidermis withdraw from the egg by means of cell contraction, releasing the egg from the zooid. This process causes a slight circular constriction of the egg surface, which moves from the distal pole to the equator. d OFE and epidermis completely retracted from the egg, which is still surrounded by the former IFE. For a short time the former OFE forms a plain pit on the surface of the abdomen. Its thickened edges pass into the epidermis. e By contraction of the epidermal cells (under increase in cell height) the former OFE is transformed into a blister-like structure with a small opening. f By fusion of its edges, the former OFE has turned into a closed hollow body (vestigial body), separated from the epidermis, which again forms the distal border of the abdomen. The epidermal cells flatten and resume their typical appearance. $E p$ epidermis, $G$ granulocytes, IFE inner follicular epithelium, $O F E$ outer follicular epithelium, Te test cells, $T u$ tunic, $V$ vestigial body
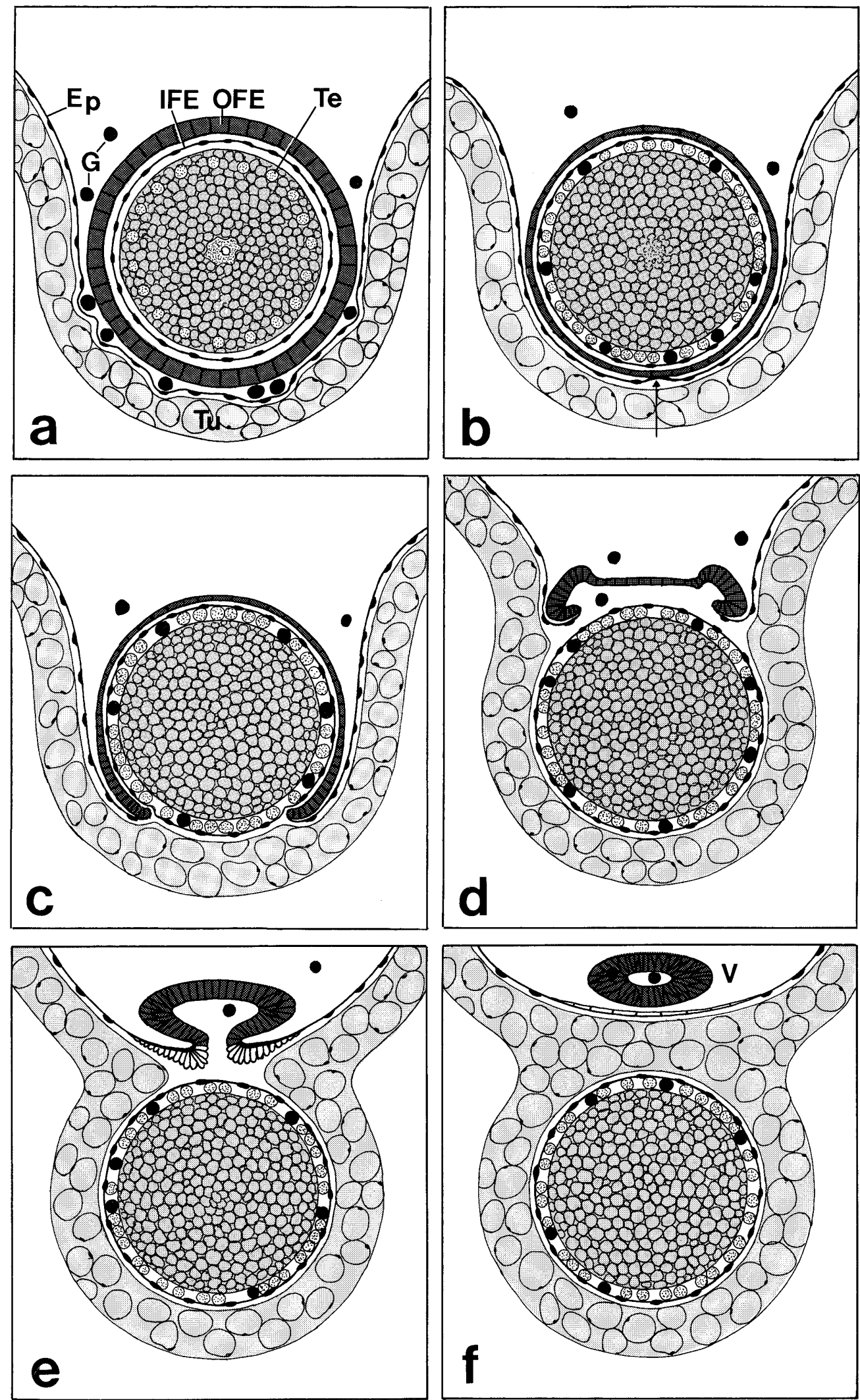
the epidermis ultimately closes above the plug, which turns into the vestigial body.

As already discussed above, granulocytes cannot be involved in the opening of the OFE. The key to a proper understanding of the opening mechanism is the present observation in D. migrans that the retracted OFE (vestigial body) is connected to the epidermis. This suggests that a fusion of both epithelia plays a decisive role in the initiation of ovulation. Tissue fusion is widespread in the embryonic development of animals. For instance, it is a fusion with the epidermis (brood pouch) and the OFE which opens the previously closed oviduct during ovulation in the ascidians Botryllus and Botrylloides (Mukai 1977; Zaniolo et al. 1987, 1994).

In the literature (Burighel et al. 1987; Martinucci et al. 1988), there is no convincing evidence of an epidermal wound occurring during ovulation. The wound on the egg surface is said to heal rapidly. Nevertheless, one would expect the egg's proximal pole to be devoid of any envelope for a short time immediately after ovulation. The observations in D. migrans, however, have clearly shown that just-ovulated eggs are completely surrounded by a coat which corresponds to the IFE. It is highly improbable that two completely different ovulation mechanisms have developed in closely related species such as $D$. $\mathrm{mi}$ grans and $D$. listerianum. There is thus every reason to believe that ovulation in $D$. listerianum follows the same pattern as that described in this paper for D. migrans.

The ovulation mechanism proposed by Martinucci et al. (1988) cannot explain the observation in D. migrans that the vestigial body is fused with the epidermis. Such a fusion does not make any sense once ovulation has occurred, but can easily be understood if we assume that OFE and epidermis fuse in the very beginning of ovulation.

\section{Vestigial body}

The vestigial body always contains a varying number of granulocytes which persist as intact cells while the other cells disintegrate. This suggests that the granulocytes are actively involved in the gradual degradation of the follicle cells.

The vestigial body is often referred to as corpus luteum (yellow body). This may be justified from the formal point of view regarding its origin. However, as far as there is no indication of an endocrine function of this structure, I prefer the neutral term "vestigial body".

Acknowledgements I thank the staff of the Biologische Anstalt Helgoland for help during my stay at the station, and especially Dr. H.-D. Franke for critical reading of the manuscript and correcting my English.

\section{References}

Berrill NJ (1950) The Tunicata. Ray Society, London

Burighel P, Martinucci GB (1994) Sexual reproduction in the compound ascidian Diplosoma listerianum (Tunicata). II. Sperm penetration through ovary wall and evidence of internal fertilization. Mar Biol 118:499-510

Burighel P, Martinucci GB, Zaniolo G (1987) Tissue repair during egg segregation in the tunic of the compound ascidian Diplosoma listerianum. Acta Embryol Morphol Exp NS 8:333-340

Fechter H (1971) Manteltiere, Schädellose, Rundmäuler. Walter de Gruyter, Berlin

Ganin M (1870) Neue Thatsachen aus der Entwicklungsgeschichte der Ascidien. Z Wiss Zool 20:512-518

Gegenbaur C (1862) Ueber Didemnum gelatinosum MilneEdwards. Arch Anat Phys Wiss Med 1862:149-168

Groepler W (1997) Morphologie, Lebensweise und Fortpflanzung von Diplosoma migrans (Ascidiacea). Accompanying publication to Film C 1855, Institut für den wissenschaftlichen Film, Göttingen, Germany

Lafargue F (1968) Les peuplement sessiles de l'archpel de Glenan. Vie Milieu 19:354-446

Lahille F (1890) Recherches sur les Tuniciers. Imprimerie Lagarde et Sebille, Toulouse

Martinucci GB, Burighel P, Zaniolo G, Brunetti R (1988) Ovulation and egg segregation in the tunic of a colonial ascidian, Diplosoma listerianum (Tunicata, Ascidiacea). Zoomorphology 108:219-227

Milne Edwards M (1842) Observations sur les Ascidiés composées des côtes de la Manche. Mem Acad Sci Paris 18:217-326

Mukai H (1977) Comparative studies on the structure of reproductive organs of four botryllid ascidians. J Morphol 152:363-380

Salensky W (1894) Beiträge zur Entwicklungsgeschichte der Synascidien. I. Ueber die Entwicklung von Diplosoma Listeri. Mitt Zool Stat Neapel 11:368-374

Satoh N (1994) Developmental biology of Ascidians. Cambridge University Press, Cambridge

Zaniolo G, Burighel P, Martinucci GB (1987) Ovulation and placentation in Botryllus schlosseri (Ascidiacea): an ultrastructural study. Can J Zool 65:1181-1190

Zaniolo G, Manni L, Burighel P (1994) Ovulation and embryoparent relationships in Botrylloides leachi (Ascidiacea, Tunicata). Invertebr Reprod Dev 25:215-226 